Kumawula, Vol. 3, No.3, Desember 2020, Hal 533 - 538 DOI: https://doi.org/10.24198/kumawula.v3i3.30915

ISSN 2620-844X (online)

Tersedia online di http://jurnal.unpad.ac.id/kumawula/index

\title{
PENGEMBANGAN POTENSI EKONOMI WILAYAH DALAM PERSPEKTIF KEWIRAUSAHAAN DI DESA KADAKAJAYA
}

\author{
Muhammad Fedryansyah $^{\mathbf{1}^{*}}$, Ramadhan Pancasilawan ${ }^{2}$, Moch. Zaenudin ${ }^{3}$ \\ ${ }^{1}$ Departemen Kesejahteraan Sosial, Universitas Padjadjaran \\ ${ }^{2}$ Departemen Administrasi Publik, Universitas Padjadjaran \\ ${ }^{3}$ Departemen Kesejahteraan Sosial, Universitas Padjadjaran \\ *Korespondensi : m.fedryansyah@unpad.ac.id
}

\begin{abstract}
ABSTRAK
Kegiatan KKN Kewirausahaan yang berlokasi di Desa Kadakajaya Kecamatan Tanjungsari Kabupaten Sumedang ini secara umum bertujuan untuk memetakan masalah dalam bidang kewirausahaan serta merancang solusi atas permasalahan tersebut secara kekeluargaan. Metode pendekatan masalah yang digunakan adalah survey kepada masyarakat untuk melakukan pemetaan potensi usaha setiap dusun, yang terdiri dari empat dusun. Dari hasil tersebut, diketahui bahwa masalah utama yang dialami oleh wirausaha di Desa Kadakajaya adalah masalah pemasaran dan arus perputaran modal. Langkah yang diambil dalam rancangan pemecahan masalah antara lain dengan menguatkan persepsi akan pentingnya One Village One Product (OVOP) sebagai tonggak utama bisnis desa. Selanjutnya, pemasaran dan penyerapan tenaga kerja yang arus modalnya bisa diintegrasikan dengan anggaran dana desa. Selain itu, juga disusun Bussiness Model Canvas untuk prototype bisnis yang dinamakan 'Kripikajaya'. Produk ini diangkat dari potensi hasil bumi atau tanaman yang ada di Desa Kadakajaya yang diolah menjadi produk makanan ringan, yaitu kripik. Desa Kadakajaya saat ini memiliki produksi pertanian unggulan yang tumbuh sepanjang tahun yaitu jamur tiram putih. Jenis tanaman lain juga dapat diolah menjadi kripik dan tumbuh di Desa Kadakajaya yang memiliki ciri rotasi tanam atau musiman seperti bayam, kangkung, singkong, dan wortel. Kemampuan masyarakat Desa Kadakajaya dalam mengolah tanaman tersebut menjadi kripik merupakan potensi yang bisa menjadi icon Desa Kadakajaya sekaligus menjadi salah satu alternatif dalam peningkatan ekonomi masyarakat.
\end{abstract}

Kata kunci : kewirausahaan, potensi ekonomi, makanan ringan.

\begin{abstract}
The activities of the Entrepreneurship KKN located in the Kadakajaya Village of Tanjungsari District of Sumedang are generally aimed at mapping problems in the field of entrepreneurship as well as devising solutions to the problem on a kinship basis. The problem approach method used is a mapping survey of the potential effort present in the four hamlets. From these results, it is known that the main problem experienced by entrepreneurs in Kadakajaya Village is the issue of marketing and the flow of capital turnover. The problem-solving design was implemented to reinforce the perception of the importance of One Village One Product (OVOP) as a key pillar of village business. Furthermore, the marketing and addition of labor whose capital flows could be integrated with the village fund budget. Business Model Canvas was also designed for a business prototype named 'Kripikajaya'. The product was selected from the potential products in Kadakajaya Village which were processed into snack food products (such as chips). The flagship agricultural production of Kadakajaya Village which grows year round is white oyster mushroom. Other types of plants that can be processed into chips and grow in Kadakajaya Village, such as spinach, kale, cassava, and carrots. The ability of the community in producing such foods to become cryptic is the iconic potential of Kadakajaya Village and can also be an alternative in the economic improvement of the community.
\end{abstract}

Keywords : entrepreneurship, economic potential, chips 


\section{PENDAHULUAN}

Pembangunan potensi wilayah merupakan upaya untuk mempercepat peningkatan perekonomian di daerah. Yolamalinda (2014) menyebutkan tantangan pembangunan ekonomi ke depan adalah mengupayakan pengelolaan yang efektif dan efisien dengan memanfaatkan secara optimal potensi wilayah termasuk sumber daya alam dan sumber daya manusianya serta seluruh sumber-sumber dana untuk membiayai pembangunan ekonomi daerah. Artinya, saat ini pembangunan ekonomi daerah dilakukan dengan cara mengoptimalkan potensi wilayahnya masing-masing. Pemanfaatan potensi ekonomi wilayah salah satunya dilakukan oleh pelaku Usaha Kecil dan Menengah selanjutnya disingkat UMKM (Muchtar et al., 2020).

Saat ini, keberadaan UMKM menunjukan peningkatan yang signifikan setiap tahunnya di Indonesia. Berdasarkan data dari Kementrian Koperasi dan Usaha Kecil Menengah, terdapat 60 juta pelaku UMKM di Indonesia (Kementerian Koperasi dan Usaha Kecil Menengah, 2019, http://www.depkop.go.id/read/kemenkop-danukm-targetkan-peningkatan-kontribusi-umkmterhadap-pdb-dan-ekspor. Angka tersebut terus bertambah seiring dengan kemajuan teknologi dan potensi sumber daya manusia. Meningkatnya jumlah UMKM menjadi salah satu faktor yang mempengaruhi pertumbuhan ekonomi. Salah satu wilayah yang memiliki potensi dimanfaatkan oleh para pelaku UMKM yaitu Desa Kadakajaya.

Berdasarkan Profil Desa Kadakajaya (2019) terdapat beberapa potensi yang dapat dikembangkan di Desa tersebut seperti potensi budaya, makanan, kerajinan tangan dan potensi sumberdaya alam. Potensi makanan ringan merupakan potensi ekonomi lokal yang banyak dimanfaatkan oleh pelaku UMKM di Desa Kadakajaya. Namun berdasarkan data dilapangan diketahui bahwa potensi yang ada belum dikembangkan secara optimal. Permasalahan tersebut meliputi kapasitas dan pengetahuan sumberdaya manusia untuk mengembangkan usaha, kemudian tidak adanya perencanaan yang jelas dalam mengembangkan potensi yang ada (Sukoco et al., 2020). Hal tersebut sejalan dengan pendapat dari Lembaga Pengembangan Perbankan Indonesia (2015) yang menyebutkan bahwa hambatan yang dihadapi para pelaku UMKM, diantaranya adalah keterbatasan modal karena tidak mendapatkan akses atau pembiayaan perbankan, sumberdaya manusia kurangnya pengetahuan mengenai teknologi, kurang mampu menangkap kebutuhan pasar, iklim usaha masih belum kondusif, prasarana dan sarana yang terbatas, serta keterbatasan akses akan bahan baku, teknologi. Oleh karena itu, diperlukan inisiasi bantuan yang dapat membantu UMKM untuk berjalan mandiri melalui perencanaan pengembanan usaha (Arifianti et al., 2018). Salah satu cara yang dapat dilakukan untuk mendorong perencanaan usaha yang efektif dapat dilakukan melalui metode bussines model canvas.

Business model canvas merupakan sebuah model bisnis mengenai gambaran perencanaan logis mengenai sebuah organisasi untuk menciptakan, menghantarkan dan menangkap sebuah nilai (Osterwalder, 2010). Model ini membagi dibagi menjadi 9 buah komponen utama yaitu Customer Segment, Customer Relationship, Customer Channel, Revenue Structure, Value Proposition, Key Activities, Key Resource, Cost Structure, dan Key Partners.

Artikel ini bertujuan untuk untuk mendeskripsikan hasil pengabdian kepada pelaku UMKM di Desa Kadakajaya dengan menggunakan metode perencanaan bussines model canvas. Kajian di dasarkan kepada hasil pelatihan yang dilakukan di Desa Kadakajaya.

\section{METODE PENELITIAN}

Metode yang digunakan dalam kegiatan PPM adalah dengan melakukan kegiatan pelatihan yang diawali terlebih dahulu dengan pemberian materi, kemudian diskusi, dan praktik. Kegiatan dipandu oleh narasumber (tenaga Ahli) sebagai fasilitator pelatihan dan dibantu dengan seperangkat alat untuk melakukan simulasi 
secara langsung. Peserta yang ikut terlibat dalam pelatihan sejumlah 15 orang yang terdiri dari pelaku UMKM serta Pemerintah Desa Kadakajaya.

Pelatihan menggunakan metode perencanaan Business model canvas Osterwalder, (2010) yang secara spesifik terdiri dari :

1. Customer Segment (CS) yaitu menentukan segmen target customer dari bisnis yang akan dikembangkan. Posisikan diri pada sisi customer untuk memperhatikan apa yang dilihat, didengar, dipikirkan dan dilakukan, menjadi keinginan dan tujuan, rasa takut, dan harapan.

2. Value Proposition (VP) yaitu memperkirakan kebutuhan customer yang sudah diidentifikasi pada customer segment.

3. Customer Relationship (CR) yaitu mendefinisikan hubungan antara perusahaan dan customer.

4. Channel $(\mathrm{CH})$ yaitu cara untuk mencapai customer. Channel ini adalah jalur antara perusahaan dengan customer, bagaimana delivery dari value yang diberikan akan mampu mencapai customer dengan baik.

5. Revenue Stream (RS) yaitu representasi dari jalur penerimaan uang yang akan diterima dari setiap customer segment.

6. Key Resource (KR) adalah Sumber Daya Utama yang menjelaskanmengenai aset terpenting yang diperlukan dalam membuat model bisnis kerja.

7. Key Activities (KA) adalah Kegiatan analisis Sumber Daya, diwajibkan untuk membuat dan melebihi Proposisi Nilai, Pencapaian pasar, mempertahankan Hubungan Pelanggan, dan pendapatan yang diperoleh, seperti Kunci Sumber Daya, kegiatan tergantung pada jenis model bisnis.

8. Key Partners (KP) adalah Kunci Kemitraan yang menjelaskan jaringan pemasok dan mitra yang membuat pekerjaan model bisnis.

9. Cost Structure adalah Struktur Biaya yang menggambarkan semua biaya yang dikeluarkan dalam mengoperasikan model bisnis ini.

\section{HASIL DAN PEMBAHASAN}

Dalam membantu perencanaan pengembangan potensi ekonomi lokal bagi pelaku UMKM di Desa Kadakajaya digunakan rancangan strategi yang bertujuan untuk memahami, memudahkan, dan memaksimalkan suatu usaha yang ada. Tahapan pertama adalah perancangan Perumusan Visi Misi Desa Kadakajaya dalam mengembangkan potensi ekonomi lokal. Berikut hasil dari perumusan visi misi tersebut yaitu :

1. Vision Statements / Hasil Ideasi Dari Pernyataan Tujuan

Visi yang telah dirumuskan adalah mengenai 'Meningkatkan pemasaran produk yang dihasilkan oleh Desa Kadakajaya'.

2. Themes / Tema Yang Akan Diangkat

1. Meningkatkan kemampuan SDM Desa Kadakajaya

2. Menciptakan strategi pemasaran produk di Desa Kadakajaya

3. Mengembangkan inovasi yang berkaitan dengan produk Desa Kadajaya

4. Mengetahui peluang pasar

5. Mengaplikasikan metode pemasaran yang tepat

3. 5 Bold Steps / 5 Tahapan Penting Dalam Mencapai Tujuan

1. Melakukan pemetaan potensi produk yang dihasilkan oleh Desa Kadakajaya

2. Membuat rancangan program intervensi yang dapat dilakukan

3. Menyelenggarakan sosialiasi mengenai program intervensi kepada masyarakat

4. Pelaksanaan program intervensi yang telah dilakukan

5. Melakukan evaluasi dan pengembangan program intervensi yang dilakukan

4. Supports / Dukungan Yang Ada Untuk Memperkuat Visi

1. Pemerintah Desa Kadakajaya 
2. Lembaga Desa (GAPOKTAN, BUMDES, LINMAS, TP PKK, KARANG TARUNA, LPM)

3. Pemilik Modal

4. Masyarakat

5. Challenges / Tantangan Dalam Mencapai Visi

1. Kurangnya pengetahuan masyarakat mengenai teknologi

2. Kurangnya intensi masyarakat mengenai pemasaran produk

3. Kurang memadainya sarana prasarana yang memadai untuk melakukan pemasaran produk

6. Values / Nilai yang terkandung dalam visi

1. Gotong royong

2. Keterbukaan

3. Kejujuran

Tahapan kedua adalah merancang strategi Business Model Canvas. Terdapat 9 komponen dalam Business Model Canvas yaitu Key Activities, Key Partners, Key Resources, Value Proposition, Customer Segments, Customer Relationships, Cost Structure, Revenue Streams, dan Channels.

Key Activities merupakan aktivitas utama/ kegiatan kunci yang dilakukan pada sebuah bisnis, seperti pada Kripikajaya, aktivitas utama dimulai dari budidaya jamur, pengolahan jamur menjadi kripik, pengemasan produk, pemasaran , distribusi produk, penerimaan feedback (saran), dan evaluasi. Pada bisnis yang diusulkan, pelaku UMKM dapat bermitra dengan petani jamur, pengrajin atau pegawai keripik, tim pemasaran produk dan distributor sebagai Key Partners dalam business model canvas. Untuk sumber daya utama atau Key Resources yang harus dimiliki dari pelaku UMKM diantaranya diantaranya ada tanaman jamur dan tanaman lain yang dibutuhkan seperti : cabe, singkong, bayam, tomat dll.

Value Propositions atau dikenal sebagai keunggulan dari produk yang kami tawarkan, dan bertujuan untuk membedakan antara bisnis yang kita miliki dengan bisnis lain. Nilai-nilai yang ingin disampaikan melalui produk
Kripikajaya ini diantaranya menjadi produk khas dari Desa Kadakajaya, dan mempromosika keripik sehat dengan cara mengubah image sayuran menjadi makanan ringnan berupa keripik.

Dalam bisnis Kripikajaya yang kita usulkan, segmentasi pasar yang ditargetkan adalah masyarakat menengah kebawah dan masyarakat penikmat sayuran. Bentuk layanan yang kami tawarkan sebagai Customer Relationship berupa layanan saran (hotline) guna mengembangkan suatu produk yang lebih unggul dan reward atau hadiah yang akan diberikan oleh pelaku bisnis kepada pelanggan guna meningkatkan minat pelanggan dalam membeli suatu produk.

Cost structure merupakan suatu bentuk pembiayaan suatu produk dalam bisnis, hal ini dinilai sebagai suatu bagian yang penting dikarenakan dapat meminimalkan risiko kerugian dalam berbisnis. Maka dari itu kita harus menentukan biaya apa saja yang dibutuhkan untuk menjalankan keseluruhan aktivitas bisnis. Salah satu bentuk pembiayaan dalam suatu produk bisnis yang diusulkan, diantaranya : bahan baku (perlengkapan), alat, gaji pegawai, overheat cost (air, listrik, dll), packaging, pengemasan, dan biaya distribusi.

Revenue stream merupakan bagian yang paling penting, dimana organisasi memperoleh pendapatan dari pelanggan. Elemen ini harus dikelola semaksimal mungkin untuk meningkatkan pendapatan bisnis. Jangan sampai ada bahan baku, produk, atau kinerja yang tidak dimanfaatkan secara maksimal. Contoh dalam bisnis yang diusulkan yaitu : penjualan produk dari online dan offline.

Channels adalah dalah media yang bisnis digunakan untuk men-deliver solusi yang kamu tawarkan untuk sampai ke konsumen. Channel ini bisa berupa online dalam bentuk $e$ commerce sedangkan offline dalam bentuk pejualan di pusat oleh-oleh, rest area dan pameran-pameran. Berikut secara lebih jelasnya gambar Business Model Canvas pelaku UMKM di Desa Kadakajaya yaitu : 


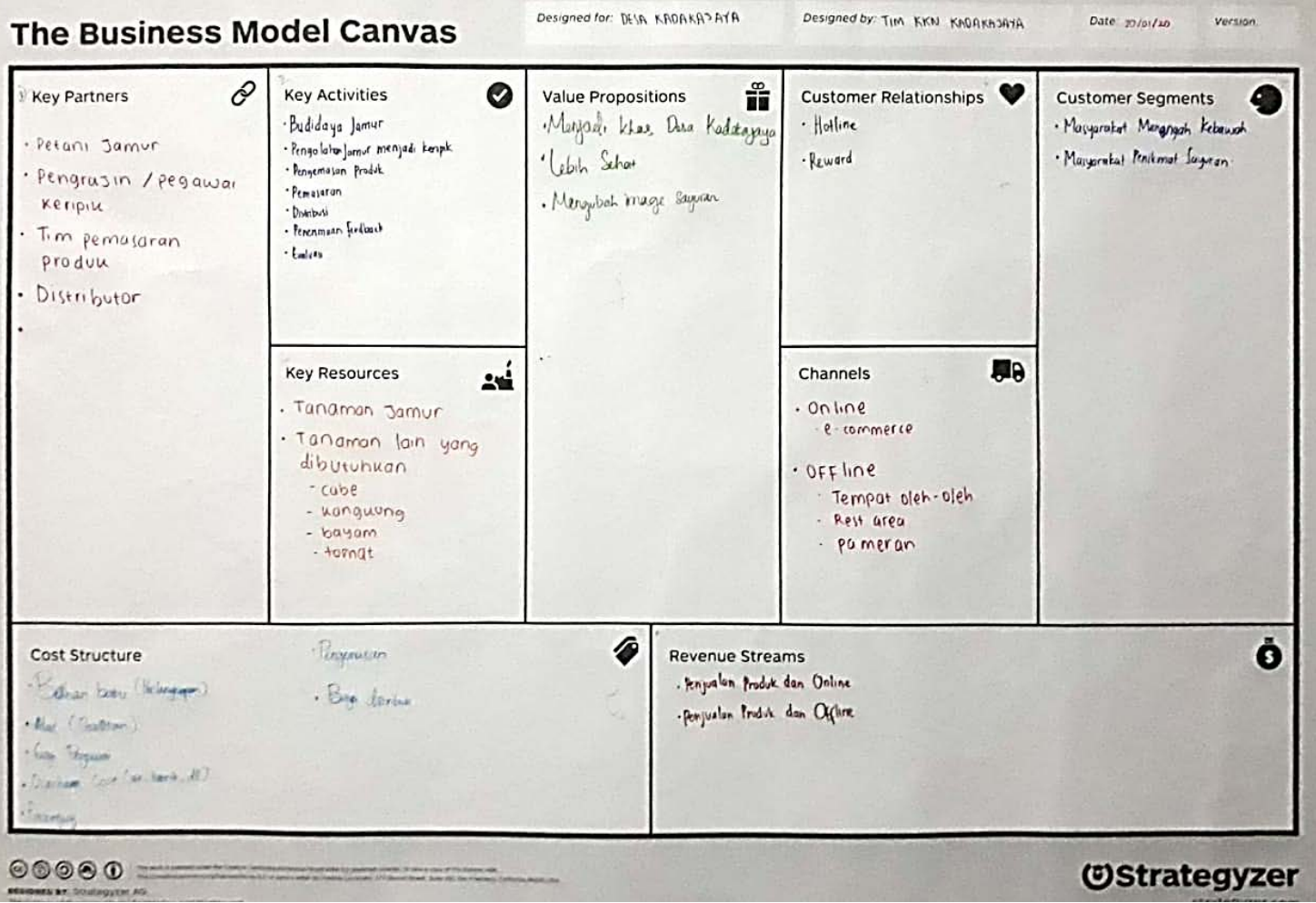

Gambar Business Model Canvas

\section{KESIMPULAN}

Desa Kadakajaya adalah desa dengan mayoritas masyarakat yang memiliki mata pencaharian yang berkaitan dengan kegiatan bercocok tanam. Usaha yang sudah berkembang kebanyakan merupakan olahan hasil alam. Hanya saja, kemampuan masyarakat masih terbatas dalam mengolah potensi tersebut menjadi sesuatu yang baru. Mereka cenderung menjual sayur-sayuran secara langsung sebagai bahan mentah, pun jamur yang menjadi usaha unggulan.

Berdasarkan hasil asessment dari potensi Desa Kadakajaya yang dilakukan, masalah utama dari usaha yang ada diantaranya : keahlian yang dimiliki oleh sumber daya manusia yang belum berkembang, keterbatasan modal, kurangnya kemampuan menguasai teknologi, dan pemasaran produk yang belum maksimal. Dan secara keseluruhan, permasalahan yang dihadapi semua wirusahawan di Desa Kadakajaya adalah pemasaran, termasuk branding. Pengembangan masyarakat berfokus membantu masyarakat mengetahui cara perencanaan usaha melalui model Business Model Canvas.

Hasil dari kegiatan dapat adalah rencana bersama dari pelaku UMKM dan pemerintah Desa Kadakajaya dalam mengembangkan potensi ekonomi lokal yaitu makanan ringan. Desa Kadakajaya memiliki banyak potensi dan setiap usaha tentunya membutuhkan sumber daya manusia. Namun, tidak dapat dipungkiri bahwa sumber daya manusia di desa ini belum memadai dikarena masih rendahnya tingkat pendidikan masyarakat desa. Padahal sumber daya manusia itu sendiri memiliki peran dan pengaruh yang sangat penting. Oleh karena itu kami memberikan saran, antara lain:

1. Adanya penyuluhan terkait keterampilan agar sumber daya manusia di Desa Kadakajaya dapat lebih berkembang dan membuka potensi-potensi lainnya

2. Pengembangan teknologi dan internet sangat diperlukan agar masyarakat dapat mempromosikan atau memasarkan produk-produknya secara 
online sehingga tingkat ekonomi masyarakat Desa dapat meningkat.

\section{DAFTAR PUSTAKA}

Lembaga Pengembangan Perbankan Indonesia. 2015. Profil Bisnis Usaha Mikro, Kecil dan Menegah (UMKM). Bank Indonesia : jakarta.

Osterwalder, Alexander dan Yves Pigneur. 2010. Business Model Generation. John Willey dan Sons, Hoboken - NJ.

Profil Desa Kadakjaya. 2019. Gambaran umum potensi potensi dan masalah Desa Kadakajaya.

Yolamalinda. 2014. Analisis Potensi ekonomi Daerah dalam Pengembangan Komoditi Unggulan Kabupaten Agam. Jorunal of Economic and economi education vol.3 No 1 (27-41)

Arifianti, R., Alexandri, M. B., \& Auliana, L. (2018). PEMETAAN AKTIVASI BISNIS KREATIF DI KECAMATAN ANDIR. Kumawula: Jurnal Pengabdian Kepada Masyarakat, 1(2), 104-113.

Muchtar, H. N., Chandrawulan, A. A., Budhijanto, D., Ikhwansyah, I., Sugiharti, D. K., Amalia, P., Trisnamansyah, P., \& Faisal, P. (2020). Potensi Umkm Di Pangandaran Dalam Menghadapi Masyarakat Ekonomi Asean. Kumawula: Jurnal Pengabdian Kepada Masyarakat, 3(2), 367. https://doi.org/10.24198/kumawula.v3i2. 24861

Sukoco, I., Fordian, D., \& -, R. (2020). Pelatihan Dasar Dan Workshop Kewirausahaan Di Desa Cintaratu Kabupaten Pangandaran. Kumawula: Jurnal Pengabdian Kepada Masyarakat, 2(3), 281. https://doi.org/10.24198/kumawula.v2i3. 24706

\section{Website :}

http://www.depkop.go.id/read/kemenkop-danukm-targetkan-peningkatan-kontribusiumkm-terhadap-pdb-dan-ekspor di unduh pada hari sabtu 29 februari 2020 pukul 15.35 